\title{
Image Case: Visualization of moving living adult worm (Entrobious) during total colonoscopy
}

\author{
Mohamed Refaey, Tarik Zaher \\ Tropical Medicine Department, Faculty of Medicine, Zagazig University, Egypt. \\ tareqzaher@gmail.com
}

Visualization of moving living adult worm(Entrobious) during total colonoscopy for 42 yrs.old male complaining of chronic diarrhea with abdominal pain.

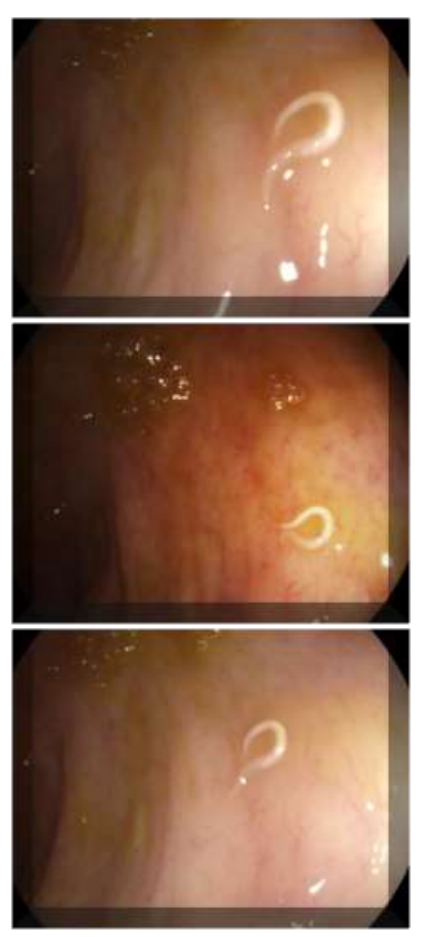

